\title{
Pembuatan Bros Dari Bahan Manik Dan Limbah Kawat Untuk Pelatihan Wirausaha Ibu Pkk Perumahan Sentra Alam Sidoarjo
}

\author{
Dyan Agustin, Wiwik Dwi Susanti \\ Universitas Pembangunan Nasional Veteran Jawa Timur \\ Dyanagustin.ar@upnjatim.ac.id
}

\begin{abstract}
Abstrak
Bros merupakan salah satu aksesoris pelengkap penampilan dalam berbusana bagi wanita yang paling banyak diminati. Bahan yang bisa digunakan untuk membuat bros bermacam macam, salah satunya adalah dari bahan manik manik dan limbah kawat. Kegiatan ini dilakukan di Perumahan Sentra Alam RT 02 yang terletak di daerah lingkar timur Sidoarjo. Diperumahan ini banyak terdapat ibu ibu PKK yang berperan sebagai ibu rumah tangga. Belum ada aktivitas yang bisa dilakukan terutama untuk menambah pemasukan dari segi ekonomi. Untuk itu diperlukan usaha untuk menambah penghasilan keluarga dengan ber wirausaha berupa pelatihan wirausaha pembuatan bros ini dari bahan manik manik dan limbah kawat. Penelitian ini termasuk penelitian deskriptif, yaitu menganalisis gambaran tentang kreatifitas ibu ibu PKK dalam mengolah manik manik dan limbah kawat menjadi produk bros. Hasil dari kegiatan pelatihan ini adalah semakin bertambahnya ketrampilan ibu ibu PKK RT 02 di Perumahan Sentra Alam Sidoarjo dengan membuat produk bros dari bahan manik manik dan limbah kawat yang layak jual. Menurut mereka pengerjaannya mudah dan bahan bahannya mudah didapatkan. Disamping itu bros yang dihasilkan terlihat unik, menarik dan tahan lama, sehingga mempunyai nilai jual yang tinggi .
\end{abstract}

Kata kunci: bros, ibu PKK, wirausaha

\begin{abstract}
Brooch is one of the accessories to complement the appearance in dressing for women who are most in demand. Materials that can be used to make brooches of various kinds, one of which is from beads and waste wire. This activity was carried out at the Sentra Alam Real Estate RT 02 located in the eastern ring area of Sidoarjo. In this house many mothers who act as housewives. There is no activity that can be done, especially to increase revenue from an economic perspective. For this reason, efforts are needed to increase family income by entrepreneurship in the form of entrepreneurship training in making brooches from beads and wire waste. This research is a descriptive study, which analyzes a picture of the creativity of PKK mothers in processing beads and wire waste into brooch products. The results of this training activity are the increasing skills of the PKK RT 02 mothers in Sidoarjo Sentra Alam Housing by making brooch products from beads and wire waste that are worth selling. According to them the process is easy and the ingredients are easy to get. Besides that, the brooches produced look unique, attractive and durable, so they have high selling points.
\end{abstract}

Keywords : brooch, PKK mother, entrepreneur 


\section{PENDAHULUAN}

Dalam dunia mode di era globalisasi sekarang ini dituntut untuk membuat inovasi. Aksesoris merupakan pelengkap dari mode yang tidak bias dipisahkan. Aksesoris atau perhiasan merupakan sebuah benda yang digunakan untuk mempercantik diri [1]. Salah satu jenis dari aksesoris bros. Bros adalah salah satu perhiasan yang dibagian belakangnya terdapat pin penahan yang berfungsi sebagai pengait [2]. Bros merupakan salah satu aksesoris pelengkap penampilan dalam berbusana bagi wanita yang paling banyak diminati. Bahan yang bisa digunakan untuk membuat bros bermacam macam, salah satunya adalah dari bahan manik manik dan limbah kawat. Bros dari bahan ini dapat digunakan untuk aksesoris dengan tampilan etnik dan sedang trend dikalangan remaja putri dan wanita dewasa. Pembuatan bros dari bahan kawat dan manik manik ini sangat mudah dikerjakan dan mudah didapatkan . Bahan manik banyak dijual di toko toko bahan kain dan menjahit, sedangkan untuk kawatnya bisa mudah didapatkan di toko elektronik. Kawat adalah bahan yang mudah dibengkokkan dan dilengkungkan dan bias dibuat berbagai macam bentuk [3] .

Kegiatan ini dilakukan di Perumahan Sentra Alam RT 02 yang terletak di daerah lingkar timur Sidoarjo. Perumahan ini bertipe $21 \mathrm{~m} 2$, yaitu tipe luasan yang tergolong kecil. Diperumahan ini banyak terdapat ibu ibu PKK yang berperan sebagai ibu rumah tangga. Pada siang hari disaat suami mereka bekerja ibu ibu pkk ini hanya bertugas menjaga anak anak mereka. Belum ada aktivitas yang bisa dilakukan terutama untuk menambah pemasukan dari segi ekonomi. Untuk itu diperlukan usaha untuk menambah penghasilan keluarga berupa pelatihan pembuatan bros ini dari bahan manik manik dan limbah kawat. Kewirausahaan sosial dapat dijadikan solusi atau model pemberdayaan masyarakat, khususnya perempuan, pada industri kerajinan [4].

Pelatihan ini merupakan program pengabdian masyarakat yang diadakan oleh dosen progdi Arsitektur UPN veteran Jawa Timur yang ditujukan untuk masyarakat yang ingin berwirausaha khususnya para ibu ibu pkk. Rumusan masalah dari kegiatan ini adalah bagaimana membuat bros dari bahan manik manik dan limbah kawat yang dilakukan oleh ibu ibu PKK agar bisa menjadi seorang wirausaha dan dapat menambah penghasilan keluarga. Setelah mengikuti pelatihan ini diharapkan peserta mampu menjadi wirausahawan dengan membuat bros dari bahan manik manik dan limbah kawat guna 
menambah penghasilan keluarga serta membangun jejaring kemitraan antara progdi arsitektur UPN veteran Jawa Timur dengan warga perumahan Sentra Alam Sidoarjo.

Ibu ibu PKK perlu diberikan bekal ketrampilan pembuatan bros ini, diharapkan produk bros tersebut bisa dijual dan dapat menambah income keluarga serta meningkatkan peran serta perempuan dalam pembangunan [4].

\section{METODE}

Berisi desain penelitian, uraian cara - cara pelaksanaan penelitian mencakup populasi dan sampel, Instrumen dan cara pengumpulan data, teknik analisis data. Hasil menyajikan karakteristik data dan temuan - temuan penelitian.

Penelitian ini termasuk penelitian deskriptif, yaitu menganalisis gambaran tentang kreatifitas ibu ibu PKK dalam mengolah manik manik dan limbah kawat menjadi produk bros. Penelitian ini dilakukan di RT 02 Perumahan Sentra Alam Sidoarjo dengan peserta 20 ibu ibu PKK. Tahap tahap yang dilakukan dalam penelitian ini antara lain :

a. Tahap perencanaan

Pada tahap perencanaan ini dilakukan penyusunan materi, pembuatan modul, membuat daftar hadir, dan membuat lembar penilaian terhadap peserta. Selanjutnya menyiapkan alat dan bahan

b. Tahap pelaksanaan

Pelaksanaan dilaksanakan pada hari kamis mulai jam 09.00 sampai jam 12.00. Tahapan pelaksanaan antara lain pengenalan alat dan bahan, penjelasan cara pembuatan dan memperlihatkan contoh-contoh. Selanjutnya praktek dengan pendampingan intens. Pelatihan dapat dilaksanakan dengan baik dengan mengedepankan keterlibatan peserta. Peserta dibekali dengan teori yang cukup untuk memulai usaha serta praktik membuat bros dengan bahan dasar kawat [5]. Setelah jadi ditunjukkan teknik pengemasan yang bagus.

c. Tahap analisis data

Analisis data dilakukan dengan mengamati kemampuan peserta pelatihan dan melihat hasil dari peserta pelatihan. Aktivitas peserta pelatihan paling baik atau aktif pada saat melakukan kegiatan mendengarkan dan melihat dimana peserta mendapatkan pengetahuan dasar keterampilan membuat bros melalui aktivitas tersebut. Semakin antusias peserta melakukan sesuatu maka akan semakin aktif atau semakin baik aktivitas peserta pelatihan [6]. 
Jurnal Pelayanan dan Pengabdian Masyarakat (PAMAS)

\section{HASIL DAN PEMBAHASAN}

Tahapan kegiatan yang sudah dilakukan pada pelatihan pembuatan bros dari bahan manik manik dan limbah kawat ini terdiri dari 3 sesi, antara lain :

Sesi 1. Kegiatan awal berisi pembukaan dan perkenalan dari tim pelatih dan peserta. Selanjutnya pemberian teori tentang konsep kewirausahaan yang meliputi pengertian kewirausahaan, ciri wirausaha, dan resiko usaha.

Kewirausahaan adalah cara berpikir dan bertindak yang mengacu pada peluang bisnis. Ciri ciri wirausaha yaitu seseorang yang memiliki percaya diri, visi misi yang terukur, jiwa kepemimpinan dan sikap kerja keras. Sedangkan untuk resiko usaha banyak factor yang mempengaruhi. Beberapa bisa mengalami kegagalan, tetapi banyak juga yang berhasil dalam menjalankan usaha. Faktor faktor penyebab kegagalan dalam berwirausaha antara lain karena :

a. Tidak kompeten dalam mengelola usaha

b. Kurang pengalaman dalam mengelola SDM

c. Belum bias mengelola keuangan

d. Gagal dalam perencanaan

e. Lokasi usaha kurang strategis

f. Sikap yang kurang serius dalam berusaha

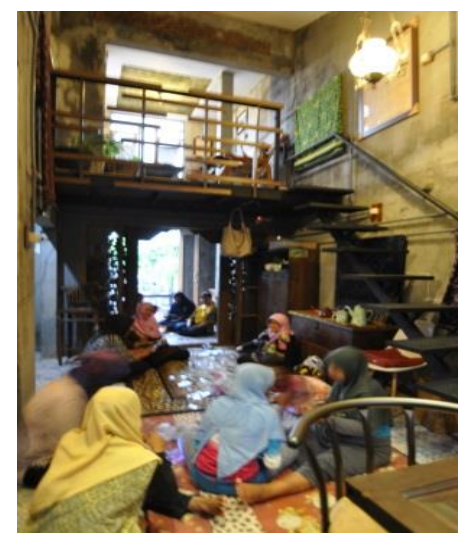

Gambar 1. Suasana pelatihan

Sesi 2. Yaitu pembekalan tentang cara memilih bahan baku, menentukan harga jual, pemasaran yang efektif. Bahan utama yang digunakan adalam manik manik. Ada beberapa cara dalam memilih manik manik, antara lain : 
a. Warna

Pemilihan warna manik merupakan hal yang penting dalam membuat bros. Karena warna menentukan tampilan dan tema yang ingin disampaikan dalam sebuah produk bros. Warna bros juga biasanya dikaitkan dengan warna baju atau hijab yang digunakan. Ada beberapa panduan dalam menggunakan warna dalam bros yang bisa disesuaikan dengan warna baju atau hijab, antara lain :

- Warna baju cerah (merah, oranye, kuning) cocok dikombinasikan dengan bros berwarna tanah dan logam seperti coklat tua, emas dan tembaga. Hal ini dimaksudkan untuk bisa membuat warna cerah baju tidak terlalu kontras dan terlihat lebih lembut.

- Warna baju hijau, cocok dikombinasikan dengan bros berwarna tanah, kayu dan bebatuan.

- Warna baju merah muda, cocok dikombinasikan dnegan bros berwarna coklat kopi, abu abu muda

b. Bahan

Bahan pembuatan manik terdiri dari jenis :

- manik akrilik

cirinya antara lain warna mengkilau, kualitas tinggi dan tidak mudah pecah, harga relative lebih mahal, warna tidak cepat pudar,

- manik non akrilik

- manik dari kayu

- manik dari bambu

Untuk pembuatan aksesorid sebaiknya dipilih bahan baku dengan kwalitas yang baik agar bisa memenuhi produktivitas dan peningkatan kualitas produk. Kualitas yang baik dilihat dari bahan baku yang asli dan model yang terkini [7].

c. Bentuk

- Manik berbentuk bulat, bentuk ini banyak diterapkan pada manik manik dan mudah diterapkan dalam bentuk bros apapun.

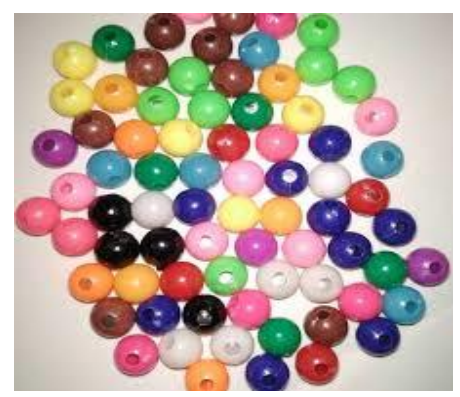

Gambar 2. Manik bentuk bulat 
- Manik berbentuk piring, berfungsi untuk dibentuk menjadi daun, sulur, batang atau ragam kreasi ronce.

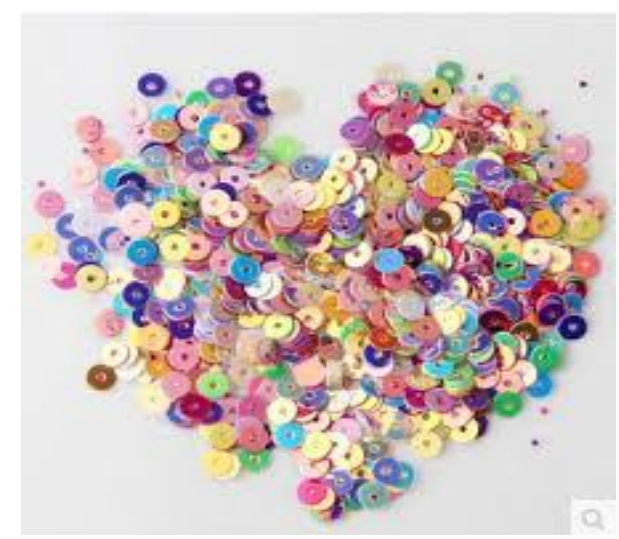

Gambar 3. Manik bentuk piring

- Manik berbentuk datar, digunakan dalam teknik sulam sisik

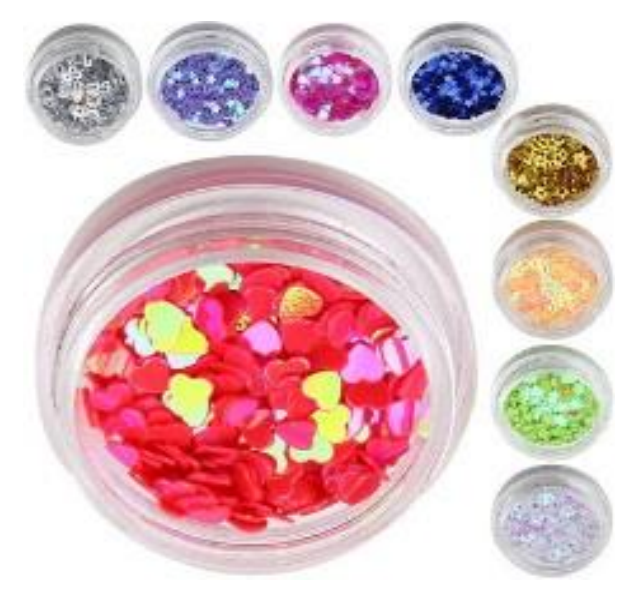

Gambar 4. Manik bentuk datar

- Manik pasir, berguna untuk mengunci manik piring

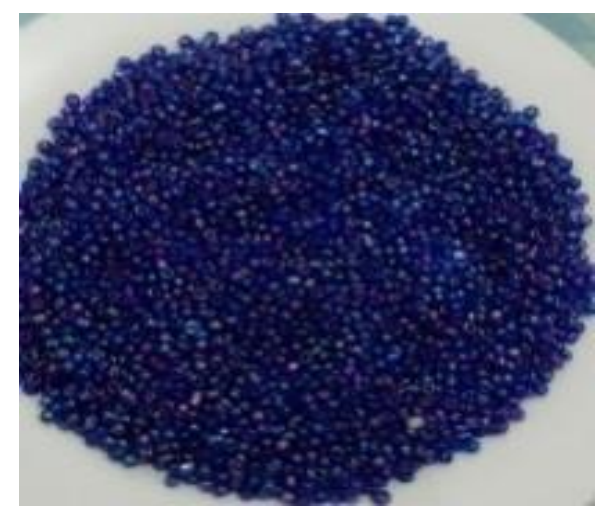

Gambar 5. Manik pasir 


\section{Jurnal Pelayanan dan Pengabdian Masyarakat (PAMAS)}

- Manik bentuk bambu

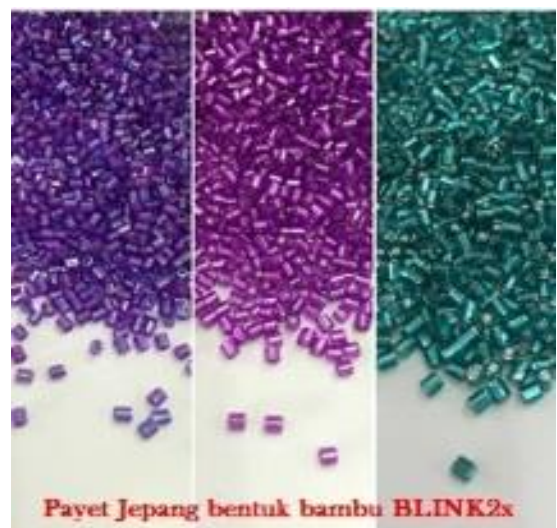

Gambar 6. Manik bentuk bambu

- Manik patahan, digunakan untuk membuat sulur dan ronce

- Manik bentuk padi

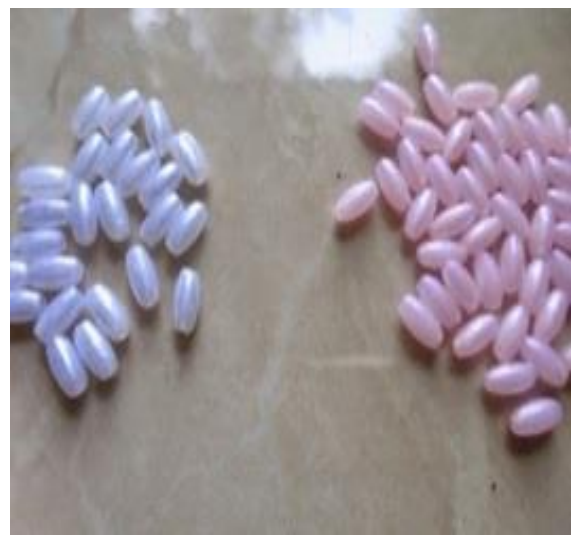

Gambar 7. Manik bentuk padi

Sedangkan untuk jenis kawat ada bermacam macam, antara lain [8].

a. Jenis kawat monel, terdapat komposisi zat besi dan mempunyai sifat kuat, sehingga sulit untuk di bengkokkan.

b. jenis kawat tembaga, mempunyai sifat kukuh dan liat, sehingga cukup mudah di bentuk.

c. jenis kawat aluminium mempunyai sifat liat dan bobot ringan sehingga mudah untuk di bentuk.

Kawat yang bisa digunakan untuk pembuatan bros ini dari bahan limbah kawat listrik. Pengolahan limbah kawat listrik menjadi produk fesyen dapat meningkatkan nilai guna serta nilai ekonomi dari limbah kabel tersebut [9].

Sesi 3. Peserta dijelaskan alat dan bahan serta cara pembuatannya. 
a. Alat dan bahan

Alat yang dibutuhkan cukup sederhana, ibu ibu PKK bisa membeli di sekitar perumahan, antara lain :

- Gunting

- Tang 3 in one

Bahan yang dibutuhkan dalam pembuatan bros dari bahan manik manik dan kawat ini antara lain :

- Manik manik dengan berbagai bentuk

- Kawat ukuran $2 \mathrm{~mm}$

- Kawat ukuran 0,4 mm

- Peniti

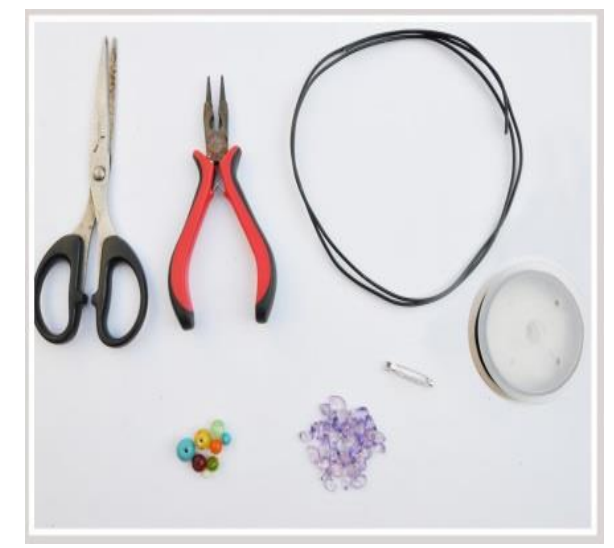

Gambar 8. Alat dan bahan

b. Cara pembuatan

- Memotong kawat $2 \mathrm{~mm}$ sepanjang $50 \mathrm{~cm}$ untuk membuat pola bentuk bros yang diinginkan. Bentuk bisa bermacam macam tergantung imajinasi desain masing masing pembuatnya.

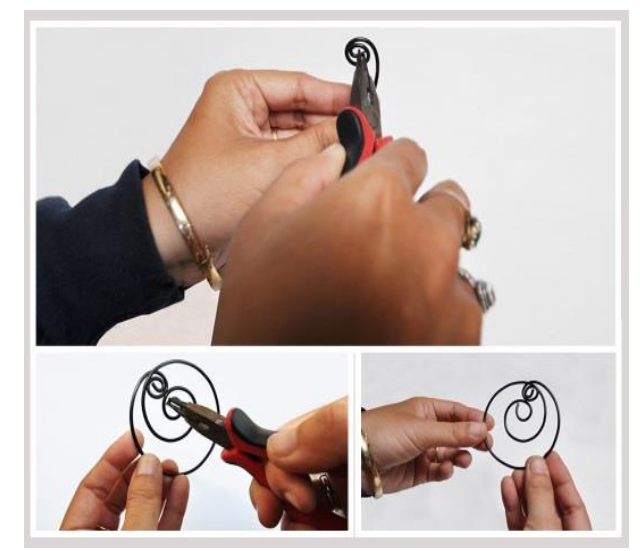

Gambar 9. Tahap membentuk pola dari kawat $2 \mathrm{~mm}$ 
- Memotong kawat 0,4 mm dengan panjang $95 \mathrm{~cm}$. Kawat o,4 mm tersebut dikaitkan dengan ujung kawat besar sehingga menyatu. Kemudian mulai memasukkan manik manik ke dalam kawat $0,4 \mathrm{~mm}$ sampai penuh.

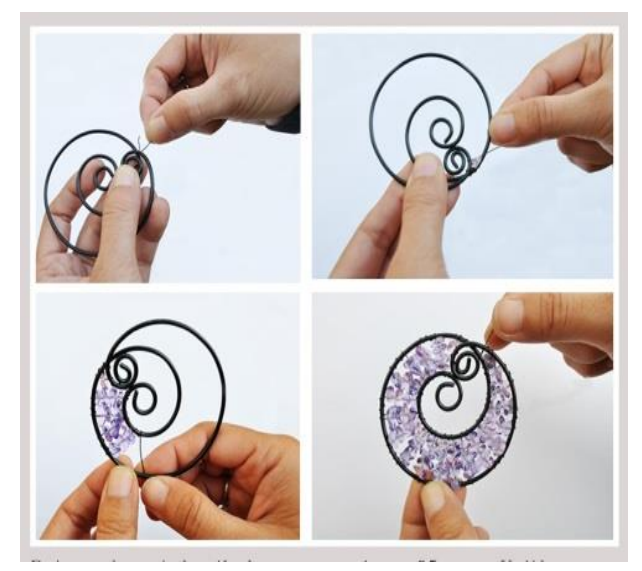

Gambar 10. Tahap mengisi pola dengan manik manik

- Pemilihan manik manik disesuaikan dengan bentuk bros. Apabila bidangnya kecil bisa diisi dengan manik manik berukuran kecil. Demikian juga sebaliknya.

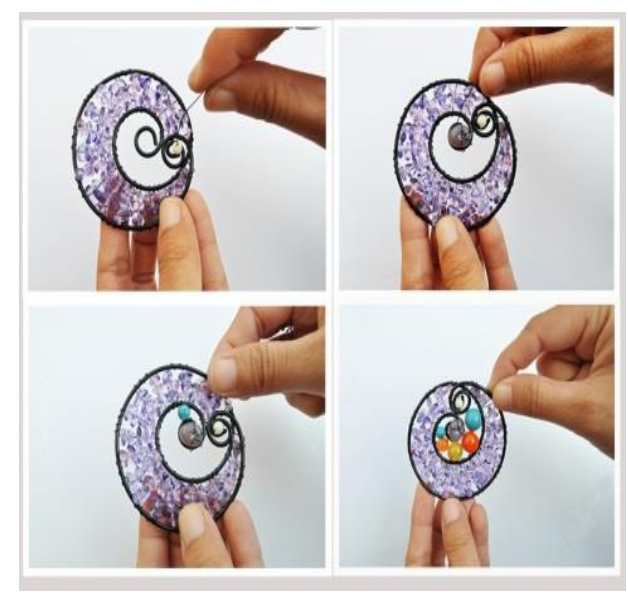

Gambar 11. Tahap mengisi pola dengan manik manik besar

- Tahap terakhir adalah memasang peniti pada bagian belakang dengan tetap menggunakan kawat $0,4 \mathrm{~mm}$ sebagai pengikat. 


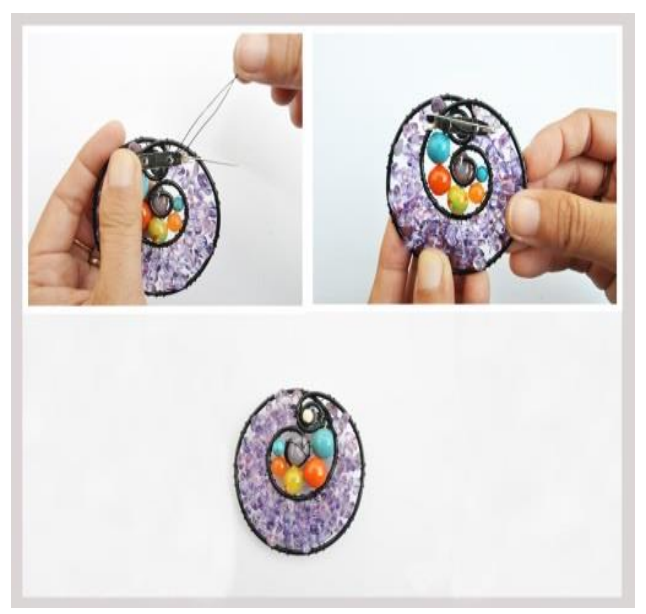

Gambar 12. Tahap menempelkan peniti dibagian belakang bros

Dari hasil pelatihan didapatkan hasil yang cukup bagus. Rata rata ibu ibu PKK tersebut bisa mengikuti dan berhasil. Karena system pembuatan bros dari manik manik dan limbah kawat ini menyerupai teknik meyulam dengan benang.

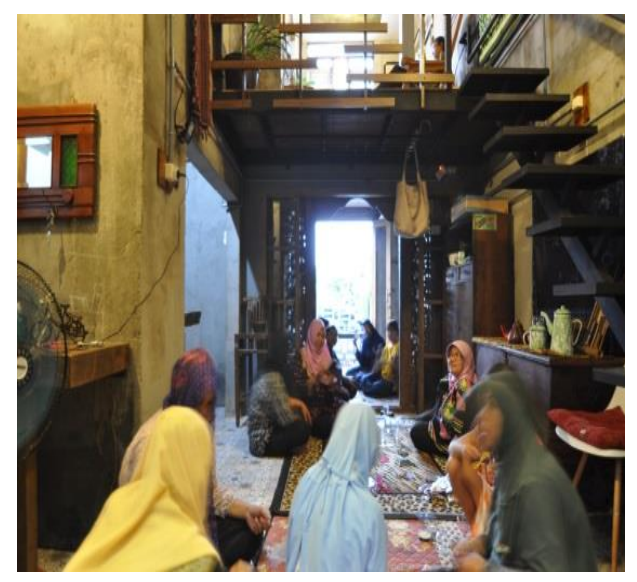

Gambar 13. Suasana pelatihan

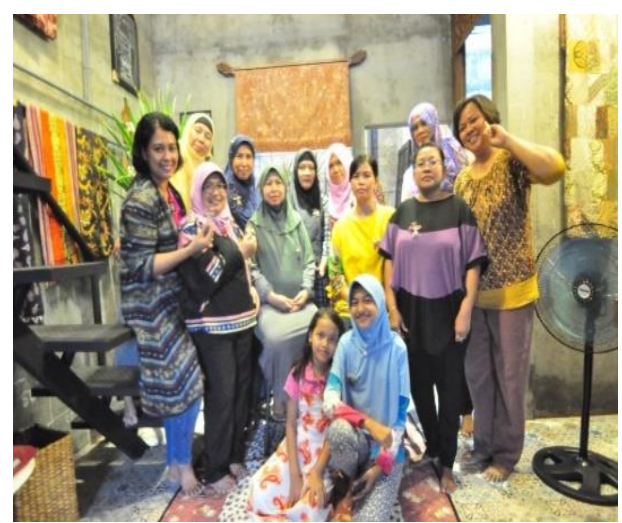

Gambar 14. Peserta Pelatihan 
Jurnal Pelayanan dan Pengabdian Masyarakat (PAMAS)

\section{SIMPULAN}

Dari pelaksanaan pelatihan pembuatan bros bari bahan manik manik dan kawat ini terlihat bahwa ketrampilan ibu ibu PKK RT 02 Perumahan Sentra alam menjadi bertambah. Dari yang semula belum mengetahui cara membuat sampai bisa membuat bros. Respon dari ibu ibu PKK tersebut sangat positif yaitu dengan hasil yang memuaskan dari bros yang berhasil di buat. Menurut mereka proses pembuatannya sangat mudah dan bahan nya pun sangat mudah didapatkan.

\section{PENUTUP}

Ucapan terimakasih diberikan kepada Progdi Arsitektur UPN veteran Jawa Timur yang telah mensuport kegiatan pelatihan ini.

\section{DAFTAR PUSTAKA}

Esther \& Lydia. Aksesori Futuristik. Surabaya :Tiara Aksa (2010).

Tortora, Phylis. The Fairchild Encyclopedia Of Fashion Accesoris. New York: Fairchild Publication (2003).

Saraswati. Membuat kalung dari kawat perak . Jakarta :: Bhratara Karya Aksara,(1982).

Vikaliana, R., \& Andayani, A. Social Entrepreneurship: Kewirausahaan Perempuan di Bogor melalui Pengolahan Kain Perca Limbah Konveksi menjadi Aksesoris. JPM (Jurnal Pemberdayaan Masyarakat), 3(2), 323-329. https://doi.org/10.21067/jpm.v3i2.2864 (2018)

Apriyanti C,.et.al . Mengubah Kawat Listrik Menjadi Aksesoris Cantik. J-Abdipamas vol 1 no 1(2017) .

Prihandayani A \& Lutfiati D . Pelatihan Keterampilan Membuat Aksesoris Rambut ( Headpiece ) dari Limbah Sisik Ikan bagi PKK Kutisari Indah Barat Surabaya. e- Journal. Volume 05 Nomer 03 Tahun 2016, Edisi Yudisium Periode Oktober (2016),.

Sharasanti, D. A., Devica, S., \& Tedjokusumo, E. P. Pkm aksesoris manik handmade di wilayah surabaya. https: // docplayer. info/164083708-Pkm-aksesoris-manikhandmade-di-wilayah-surabaya.html (2018).

Nurjanah S \& Yulistiana . Pengaruh Jenis Kawat Terhadap Hasil Jadi Bros. e-Journal. Volume 04 Nomor 01 Tahun 2015, Edisi Yudisium Periode Pebruari (2015).

Fatmawati, T. Pengolahan Kawat Tembaga Limbah Kabel Untuk Produk Fashion. Skripsi S1Progdi Kriya Tekstil Mode Universitas Telkom (2015). 
Jurnal Pelayanan dan Pengabdian Masyarakat (PAMAS) 